Лекция

\title{
Эозинофильные поражения
}

\section{желудка и кишечника:}

\section{клиника, диагностика, лечение}

Корниенко Е.А.' • Моисеенкова Ю.А. ${ }^{2}$ Волкова Н.Л. ${ }^{1}$ Лобода Т.Б. ${ }^{1}$

Корниенко Елена Александровна д-р мед. наук, профессор, заведующая кафедрой гастроэнтерологии факультета послевузовского

и дополнительного профессионального образования'

$\triangle 194100$, г. Санкт-Петербург, ул. Литовская, 2, Российская Федерация Тел.: +7 (812) 7780661.

E-mail: elenkornienk@yandex.ru

Моисеенкова Юлия Андреевна - врач гастроэнтерологического отделения ${ }^{2}$

Волкова Наталья Леонидовна заведующая гастроэнтерологическим отделением клинической больницы ${ }^{1}$

Лобода Татьяна Борисовна канд. мед. наук, доцент кафедры гастроэнтерологии факультета послевузовского и дополнительного профессионального образования'
Эозинофильные заболевания желудочно-кишечного тракта (ЖКТ) - недостаточно изученная патология, тенденция к росту которой, наблюдающаяся в последние годы, вызывает тревогу. Они могут иметь весьма вариабельные клинические проявления, поэтому дифференциальный диагноз нередко представляет большие сложности. В статье дан обзор научных данных по проблеме эозинофильных заболеваний ЖКТ и приведены 3 клинических примера различных эозинофильных поражений желудка и кишечника у детей. Клиническая манифестация эозинофильных заболеваний ЖКТ зависит от локализации и глубины поражения. В первом клиническом примере описан случай повторных желудочных кровотечений у ребенка с геморрагическим эозинофильным гастритом, во втором - эозинофильного колита с клинической и эндоскопической картиной, напоминающей болезнь Крона, и в третьем - случай асцита на фоне эозинофильного илеоколита. Все наблюдаемые нами дети имели в основе заболевания сенсибилизацию к различным пищевым аллергенам, но ни в одном случае в крови не было повышения специфических $\lg \mathrm{E}$, однако $\lg \mathrm{E}$ обнаружены в биоптате слизистой оболочки кишечника, в дуоденальном аспирате. Тест дегрануляции тучных клеток с соответствующими аллергенами коррелировал с эффективностью их элиминации. Элиминационная диета была назначена всем больным, в двух случаях - В сочетании с коротким курсом глюкокортикостероидов, в одном - продолжена назначением монтелукаста. У всех трех пациентов достигнуто полное выздоровление, которое подтверждено динамическим наблюдением, повторным эндоскопическим и гистологическим исследованием.

Ключевые слова: эозинофильный гастрит, эозинофильный гастроэнтерит, эозинофильный колит, эозинофильные заболевания желудочно-кишечного тракта

Для цитирования: Корниенко $E A$, Моисеенкова ЮА, Волкова НЛ, Лобода ТБ. Эозинофильные поражения желудка и кишечника: клиника, диагностика, лечение. Альманах клинической медицины. 2018;46(5):482-496. doi: 10.18786/2072-0505-201846-5-482-496.

Поступила 17.08.2018;

принята к публикации 25.09.2018

'ФГБОУ ВО «Санкт-Петербургский государственный педиатрический медицинский университет» Минздрава России; 194100, г. Санкт-Петербург, ул. Литовская, 2, Российская Федерация

${ }^{2}$ СПБ ГБУз «Детская городская больница № 2 святой Марии Магдалины» г. Санкт-Петербурга; 199053, г. СанктПетербург, 2-я линия Васильевского острова, 47, Российская Федерация 
$\mathrm{B}$ последние годы во всем мире, включая Россию, отмечается рост частоты пищевой аллергии у детей, особенно к белкам коровьего молока [1]. Проблема эозинофильных поражений желудочно-кишечного тракта (ЖКТ), которая частично перекликается с проблемой пищевой аллергии, освещается в меньшей степени и зачастую ограничивается лишь эозинофильным эзофагитом. Однако спектр эозинофильных заболеваний ЖКТ гораздо шире, они могут иметь различные «маски», что затрудняет своевременную диагностику и лечение. Мы даем краткий обзор современных представлений о данной проблеме и приводим несколько примеров эозинофильных заболеваний желудка и кишечника у детей из собственной практики.

\section{Патогенез}

Эозинофильные заболевания ЖКТ - редкие хронические иммунопатологические заболевания, протекающие с преимущественно эозинофильным воспалением различных отделов ЖКТ. Большинство таких пациентов составляют взрослые, подростки и дети старшего возраста, тем не менее эозинофильные заболевания ЖКТ встречаются в любом возрасте, в том числе у детей до 1 года [2]. Примерно у 30-40\% больных в сыворотке крови обнаруживают невысокие концентрации специфических иммуноглобулинов (Ig) E. В связи с этим эозинофильные заболевания ЖКТ классифицируют как аллергические заболевания со смешанным механизмом, IgE- и неIgE-опосредованным [3]. Особое место принадлежит эотаксину - это селективный хемокин, регулирующий миграцию эозинофилов, он связывается с рецепTором CCR3 на поверхности эозинофила, что приводит к последующей активации выработки цитокинов, в первую очередь интерлейкинов (IL)
3, 5 и 13 [4]. Клинически для эозинофильных заболеваний ЖКТ характерно отсроченное развитие симптомов и отсутствие типичных для реагинового механизма проявлений со стороны кожи и респираторной системы [5]. Традиционно механизм эозинофильных заболеваний ЖКТ связывают с доминированием Th2-иммунного ответа. Однако в последнее время появились новые гипотезы, в частности, связи с IgG4 [6].

\section{Классификация}

Наиболее раннее описание серии пациентов с различными абдоминальными симптомами и интестинальной эозинофилией принадлежит шведскому хирургу R. Kaijser (1937). B 1970 г. N.C. Klein и соавт. выделили несколько типов интестинальной эозинофилии в зависимости от максимально вовлеченного в воспалительный процесс слоя: слизистый, мышечный и серозный (табл. 1) [7].

При эозинофильных заболеваниях ЖКТ могут поражаться любые отделы ЖКТ, как изолированно, так и сочетанно. Именно поэтому в современной классификации первичные эозинофильные заболевания ЖКТ различают по основному вовлеченному органу [8], соответственно, выделяют:

- эозинофильный эзофагит;

- эозинофильный гастрит;

- эозинофильный гастроэнтерит;

- эозинофильный колит.

\section{Роль эозинофилов в норме и при патологии}

В слизистой оболочке ЖКТ эозинофилы могут обнаруживаться при воспалительных реакциях вследствие различных причин и служат неспецифическим признаком хронического воспаления. В этой связи очень важно перед установлением диагноза эозинофильного желудочно-кишечного

Таблица 1. Признаки эозинофильных форм заболеваний желудочно-кишечного тракта в зависимости от глубины поражения [7]

\begin{tabular}{|c|c|c|c|c|c|}
\hline Форма & Частота, \% & Глубина поражения & Поражаемые органы & Ведущие симптомы & $\begin{array}{l}\text { Признаки (эндоскопические } \\
\text { и лучевые) }\end{array}$ \\
\hline Слизистая & $45-80$ & $\begin{array}{l}\text { Слизистая оболочка } \\
\text { и подслизистый слой }\end{array}$ & Пищевод, желудок, кишечник & $\begin{array}{l}\text { Боли в животе, потеря } \\
\text { массы тела, диарея, } \\
\text { рвота, мальабсорбция, } \\
\text { дефицит Fе, экссудативная } \\
\text { энтеропатия }\end{array}$ & $\begin{array}{l}\text { Гиперемия, отек, утолщение } \\
\text { складок, эрозии, язвы }\end{array}$ \\
\hline Мышечная & $12-30$ & Мышечный слой & $\begin{array}{l}\text { Пищевод, желудок, тонкая } \\
\text { кишка }\end{array}$ & $\begin{array}{l}\text { Тошнота, рвота, дисфагия, } \\
\text { боли в животе, } \\
\text { пилоростеноз или } \\
\text { кишечная непроходимость }\end{array}$ & $\begin{array}{l}\text { Стриктуры, ригидность, } \\
\text { дисмоторика и обструкция }\end{array}$ \\
\hline Серозная & $12-39$ & $\begin{array}{l}\text { Серозная и субсерозная } \\
\text { оболочка }\end{array}$ & Кишечник & Асцит и перитонит & $\begin{array}{l}\text { Эозинофильный асцит, } \\
\text { перфорация тонкой кишки }\end{array}$ \\
\hline
\end{tabular}


Таблица 2. Биологические эффекты эозинофилов при патологии

\begin{tabular}{|c|c|c|}
\hline Класс & Пример & Биологический эффект \\
\hline \multirow[t]{3}{*}{ Ферменты } & Эозинофильная пероксидаза & Токсическое воздействие на «мишени» \\
\hline & & Триггеры высвобождения гистамина из тучных клеток \\
\hline & Эозинофильная коллагеназа & Ремоделирует матрикс соединительной ткани \\
\hline \multirow[t]{3}{*}{ Токсичный белок } & Основной белок & Токсичен к паразитам, триггер высвобождения гистамина \\
\hline & Эозинофильный катионный белок & Токсичен к паразитарным клеткам \\
\hline & Эозинофильный нейротоксин & Нейротоксичен \\
\hline Цитокины & IL-3, IL-5, GM-CSF & Повышают продукцию эозинофилов в костном мозге, активируют эозинофиль \\
\hline Хемокины & CXCL8 (IL-8) & Хемотаксис нейтрофилов \\
\hline \multirow[t]{3}{*}{ Лейкотриены } & C4, D4, E4 & Усиливают сокращения гладких мышц \\
\hline & & Повышают проницаемость сосудов \\
\hline & & Повышают секрецию слизи \\
\hline Липидные медиаторы & Фактор активации тромбоцитов (PAF) & Активирует тромбоциты, эозинофилы, нейтрофилы \\
\hline
\end{tabular}

заболевания исключить другие возможные причины вторичной эозинофилии [9]:

- паразитарные инвазии (лямблиоз, изоспороз, гельминтозы);

- системные воспалительные заболевания (воспалительные заболевания кишечника, диффузные заболевания соединительной ткани, васкулиты);

- первичный гиперэозинофильный синдром;

- лекарственное воздействие (напроксен, клозапин, рифампицин, препараты золота).

В норме эозинофилы в небольшом количестве присутствуют в слизистой оболочке ЖКТ, выполняя физиологические функции, прежде всего регенерации. При активации они оказывают повреждающее действие на ткани, поддерживая воспаление и способствуя формированию фиброза (табл. 2). Эозинофильное воспаление приводит к структурным изменениям, известным как ремоделирование. Наиболее клинически значимый элемент этого феномена - гипертрофия гладких мышц с субэпителиальным отложением коллагена, что приводит к фиброзу и сужению просвета органа. Этот процесс был продемонстрирован в бронхах у больных бронхиальной астмой и в пищеводе у больных эозинофильным эзофагитом [10, 11]. Ремоделированием объясняется как нарушение моторики ЖКТ, так и формирование стриктур и обструктивных осложнений при эозинофильных заболеваниях ЖКТ. Фиброз стромы, который нередко обнаруживают при гистологическом исследовании биоптатов больных эозинофильными заболеваниями ЖКТ, имеет прямое отношение к эозинофилам. Главный базовый белок эозинофилов повышает экспрессию гена FGF-9, который усиливает пролиферативные процессы в ткани. Эозинофилы также продуцируют большое количество CCL18 - хемокина 2-го типа, участвующего в фиброзном ремоделировании через пролиферацию фибробластов и отложение коллагена [10]. Однако в наибольшей степени доказана роль TGF- $\beta$ в усилении фиброзного ремоделирования, экспрессия которого усилена при эозинофильных заболеваниях ЖКТ и у детей, и у взрослых [10-13].

\section{Диагностика}

До настоящего времени нет строгих нормативов допустимого количества эозинофилов в различных органах пищеварения у детей и взрослых. Диагноз эозинофильных заболеваний ЖКТ устанавливают, как правило, по наличию скопления эозинофилов в сочетании с отеком, обычно вовлекаются подслизистый и любые другие слои стенки органа. Важны проявления дегрануляции эозинофилов, эозинофильного криптита и фиброза, которые считаются безусловными признаками эозинофильного поражения. В пищеводе эозинофилы в норме отсутствуют, в желудке, как в теле, так и в антральном отделе, а также в проксимальных отделах тонкой кишки они присутствуют в небольшом количестве (до 10 в поле зрения), в подвздошной и толстой кишке их число может доходить до 20 в поле зрения [3]. 
Таблица 3. Диагностические критерии эозинофильных заболеваний желудочно-кишечного тракта: количество эозинофилов, гистологические признаки и клинические проявления

\begin{tabular}{|c|c|c|c|c|}
\hline Орган & $\begin{array}{l}\text { Среднее количество } \\
\text { эозинофилов в норме (EOS } \\
\text { в } 1 \text { ПЗБУ) }\end{array}$ & $\begin{array}{l}\text { Минимальное количество } \\
\text { эозинофилов для диагноза }\end{array}$ & Гистологические изменения & Клинические проявления \\
\hline Пищевод & $>5$ & $\geq 15$ в эпителиальном слое & $\begin{array}{l}\text { Удлинение сосочков } \\
\text { и гиперплазия базального } \\
\text { слоя с эозинофильной } \\
\text { инфильтрацией lamina propria } \\
\text { и мышечного слоя }\end{array}$ & $\begin{array}{l}\text { Дисфагия, ГЭРБ-подобные } \\
\text { симптомы }\end{array}$ \\
\hline Желудок & $\begin{array}{l}\text { 1-2 эозинофила в lamina propria, } \\
\text { отсутствие межэпителиальных } \\
\text { эозинофилов }\end{array}$ & $>20$ & $\begin{array}{l}\text { Скопления эозинофилов } \\
\text { на поверхности, отек, } \\
\text { дегрануляция эозинофилов }\end{array}$ & $\begin{array}{l}\text { Боли, тяжесть в эпигастрии, } \\
\text { тошнота, рвота, возможен } \\
\text { пилоростеноз }\end{array}$ \\
\hline $\begin{array}{l}\text { Двенадцатиперстная } \\
\text { кишка }\end{array}$ & $\begin{array}{l}\text { До } 10 \text { эозинофилов в lamina } \\
\text { propria, единичные } \\
\text { межэпителиальные } \\
\text { эозинофилы }\end{array}$ & $>20$ & $\begin{array}{l}\text { Скопления эозинофилов } \\
\text { на поверхности, отек, } \\
\text { дегрануляция эозинофилов, } \\
\text { криптит. Эозинофильная } \\
\text { инфильтрация lamina propria, } \\
\text { мышечного или серозного } \\
\text { слоя. Гипертрофия мышечного } \\
\text { слоя }\end{array}$ & $\begin{array}{l}\text { Боли в животе, диарея, потеря } \\
\text { массы тела, мальабсорбция, } \\
\text { возможны пилоростеноз, } \\
\text { перфорация и асцит }\end{array}$ \\
\hline Подвздошная кишка & $\begin{array}{l}\text { До } 15 \text { эозинофилов в lamina } \\
\text { propria, единичные } \\
\text { межэпителиальные } \\
\text { эозинофилы }\end{array}$ & $>20-30$ & $\begin{array}{l}\text { Скопления эозинофилов } \\
\text { на поверхности, отек, } \\
\text { дегрануляция эозинофилов, } \\
\text { криптит. Эозинофильная } \\
\text { инфильтрация lamina propria, } \\
\text { мышечного или серозного } \\
\text { слоя. Гипертрофия мышечного } \\
\text { слоя }\end{array}$ & $\begin{array}{l}\text { Боли в животе, возможна } \\
\text { перфорация или обструкция } \\
\text { тонкой кишки, возможен асцит }\end{array}$ \\
\hline Толстая кишка & 10-30 эозинофилов & $\begin{array}{l}>20-50 \text { эозинофилов } \\
\text { в зависимости от } \\
\text { локализации, в правых } \\
\text { отделах выше, чем в левых }\end{array}$ & $\begin{array}{l}\text { Эозинофильная } \\
\text { и лимфоцитарная } \\
\text { инфильтрация lamina } \\
\text { рropria, межэпителиальные } \\
\text { эозинофилы, эозинофилы } \\
\text { в криптах }\end{array}$ & $\begin{array}{l}\text { Диарея, кровь в стуле, боли } \\
\text { в животе, запоры }\end{array}$ \\
\hline
\end{tabular}

ПЗБУ - поле зрения при большом увеличении, ГЭРБ - гастроэзофагеальная рефлюксная болезнь

Однако строгая верхняя граница нормы установлена только для пищевода - 15 в поле зрения при большом увеличении [14]. Для остальных отделов условно взята цифра 20-30 в поле зрения, но, возможно, она в дальнейшем будет уточнена (табл. 3).

Примерно треть больных с эозинофильными заболеваниями ЖКТ имеют ту или иную сопутствующую атопическую патологию: бронхиальную астму, аллергический ринит, дерматит, отягощенную наследственность по атопии или отмечали аллергические реакции на лекарства [2]. Установлен ряд генов, которые контролируют функции тучных клеток, активацию и рекрутинг эозинофилов, они, вероятно, могут предрасполагать к развитию эозинофильных заболеваний ЖКТ: это гены, контролирующие образование и функции эотаксина-3 (CCL26), карбоксипептидазы-А3 (CPA3), триптазы (TPSAB1) и высокоаффинного рецептора IgE (FCeRI) $[15,16]$.

\section{Клинические проявления различных форм эозинофильных заболеваний желудочно-кишечного тракта}

Эозинофильный эзофагит - наиболее частая форма эозинофильных заболеваний ЖКТ, хроническое иммунопатологическое заболевание пищевода, клинически проявляющееся симптомами эзофагеальной дисфункции, а гистологически - преимущественно эозинофильным воспалением [17].

Провоцирующими факторами эозинофильного эзофагита оказываются пищевые, а иногда и аэроаллергены. Заболевание встречается в любом возрасте, преобладают лица мужского пола. В странах с западным образом жизни распространенность эозинофильного эзофагита значительно выросла за последние десятилетия и практически сравнялась с таковой болезни Крона - 40-55 на 100 тыс. жителей [18]. Как нами 
описано ранее [19], эозинофильный эзофагит проявляется симптомами, сходными с признаками гастроэзофагеальной рефлюксной болезни (ГЭРБ), но, как правило, рефрактерными к стандартному лечению. У детей может наблюдаться отказ от еды, срыгивание и рвота, затруднение при глотании твердой или сухой пищи, недостаток массы тела. Признаки атопии выявляются далеко не всегда, физикальный осмотр и стандартные лабораторные показатели обычно в пределах нормы, за исключением периферической эозинофилии, которая обнаруживается у половины пациентов с эозинофильным эзофагитом $[20,21]$. Повышение общего IgE (более 114 кЕд/л) отмечается в 50-60\% [22]. Интересно, что среди пациентов с эозинофильным эзофагитом довольно высока распространенность сенсибилизации к аэроаллергенам, как бытовым, так и пыльцевым: от 71 до 93\% по кожным скарификационным пробам, согласно разным оценкам [21]. Среди педиатрических пациентов с эозинофильным эзофагитом, обследованных E.A. Erwin и соавт., сенсибилизация к ингаляционным аллергенам была столь же распространена, что и к пищевым [22], наиболее часто - к клещам домашней пыли, пыльце деревьев и трав. В подтверждение значимости пыльцевой сенсибилизации ряд ретроспективных исследований констатировали снижение частоты случаев эозинофильного эзофагита в зимний и увеличение в весенне-летний период [23-25].

Диагноз устанавливается на основании симптомов эзофагеальной дисфункции, характерной гистологической картины биоптата слизистой оболочки пищевода, взятого при проведении эзофагогастродуоденоскопии (ЭГДС), и исключения ГЭРБ [26]. Согласно рекомендациям по диагностике и ведению эозинофильного эзофагита у детей и взрослых 2017 г., для гистологического подтверждения эозинофильного эзофагита необходимо обнаружение 15 или более интраэпителиальных эозинофилов в поле зрения при большом увеличении $(\times 400)$ хотя бы в одном из шести биоптатов, взятых из разных отделов пищевода [27].

Эндоскопически в пищеводе при эозинофильном эзофагите часто визуализируются линейные складки и борозды, расположенные продольно. Характерны кольцевые складки слизистой («трахеализация» пищевода), нередко обнаруживают изъязвления, белесые налеты, иногда уже сформированные стриктуры пищевода [27]. На слизистой пищевода могут наблюдаться микроузелки, при гистологическом исследовании содержащие агрегаты лимфоцитов и эозинофилов.

Обнаружение эозинофилов в слизистой оболочке пищевода не всегда обусловлено эозинофильным эзофагитом [28-30]. По данным исследования M.E. Rothenberg и соавт., небольшая эозинофилия (до 7 эозинофилов в поле зрения при 400-кратном увеличении) часто бывает при ГЭРБ, но более 15 эозинофилов в поле зрения - только при эозинофильном эзофагите [31]. Примерно у трети больных эозинофильным эзофагитом эозинофилия пищевода уменьшается или исчезает на фоне лечения препаратами ингибиторов протонной помпы. Их эффективность не исключает диагноз эозинофильного эзофагита, поскольку клиническая, эндоскопическая и морфологическая картина, а также генетическая предрасположенность к заболеванию в случае наличия или отсутствия ответа на терапию ингибиторами протонной помпы не различаются, что свидетельствует об одном и том же заболевании. Таким образом, возможны две формы эозинофильного эзофагита: чувствительный и нечувствительный к ингибиторам протонной помпы [26].

В отличие от эозинофильного эзофагита, эозинофильное поражение желудка и кишечника встречается значительно реже: 3-8 на 100 тыс. [2] и не имеет столь четких клинических и эндоскопических критериев диагностики [10]. До сих пор нет общего мнения о количестве эозинофилов в биоптатах различных участков ЖКТ, достаточном для установления диагноза. Не разработаны и единые подходы к лечению этих заболеваний. Именно поэтому описание клинических примеров эозинофильных заболеваний ЖКТ разной локализации у детей может способствовать улучшению знаний врачей об этой пока редкой, но растущей патологии. Мы приводим три собственных наблюдения детей с эозинофильными заболеваниями ЖКТ разной локализации.

Эозинофильный гастрит может манифестировать абдоминальной болью (в том числе острой по типу «острого живота»), рвотой. Приступ обычно провоцируется приемом аллергена, но при регулярном поступлении рвота может повторяться. Рвота может быть с кровью, «кофейной гущей». При этом в желудке эндоскопически можно видеть мелкие геморрагические эрозии. Реже обнаруживают более крупные эрозии и даже язвы, которые не поддаются обычной антисекреторной или эрадикационной терапии. Кровопотеря может быть весьма значимой и требующей заместительных гемотрансфузий. В редких случаях при глубоком поражении эозинофильный гастрит 
может осложняться формированием пилоростеноза [5].

\section{Клинический пример 1}

Больная А., 1 год 2 месяца. Поступила в стационар экстренно в связи со рвотой «кофейной гущей».

Из анамнеза известно, что ребенок от 2-й беременности, роды срочные, родилась с весом 3350 г, длиной 50 см, оценка по Апгар 9/9 баллов, на грудном вскармливании до 1 года 1 месяца. Прикормы с 7 месяцев. Периодические высыпания на коже с 4 месяцев, с момента введения прикормов отмечено усиление высыпаний, учащение стула, затем высыпания прошли, после года появились запоры.

В связи с запорами в течение недели перед госпитализацией мать самостоятельно давала девочке льняное масло. Через 7 дней его приема и появилась рвота «кофейной гущей», по поводу которой девочка экстренно госпитализирована в больницу. При поступлении - черный стул, состояние тяжелое, бледная, вялая. В крови: гемоглобин 33 г/л, коагулограмма без патологии, тромбоциты $328 \times 10^{9} /$ л. Проведена экстренная ЭГДС - в просвете желудка остатки старой крови, источник кровотечения не найден.

Получила две трансфузии эритроцитарной массы, показатели крови улучшились. Выписана домой.

Через 1 месяц вновь появился черный стул, экстренно госпитализирована в больницу. При поступлении - гемоглобин 61 г/л, на экстренной ЭГДС в желудке остатки старой крови, источник кровотечения не найден. В связи с подозрением на аномалию сосудов сделана ангиография и лапароскопия - патологии не выявлено. Для уточнения диагноза в связи с сохранением признаков кровотечения (сохранение анемии, черный стул) переведена в специализированное гастроэнтерологическое отделение Санкт-Петербургского государственного педиатрического медицинского университета.

При поступлении в анализе крови: гемоглобин 73 г/л, тромбоциты $365 \times 10^{9} /$ л, общий белок 50 г/л, общий и специфические IgE в норме.

Проведена ЭГДС (рис. 1): на стенках тела и дна желудка сгустки свежей крови. Слизистая бледная, отечная. Патологических образований не выявлено. При отмывании слизистой оболочки тела и дна желудка отмечено диффузное «просачивание» крови с обширных участков слизистой («плачущий кровью желудок»). Локальных источников кровотечения не выявлено. Заключение - эндоскопическая картина соответствует геморрагическому гастриту.

Гистологически (рис. 2 А и Б) обнаружена инфильтрация собственной пластинки слизистой оболочки желудка с большим количеством эозинофилов (более 20 в поле зрения при большом увеличении).

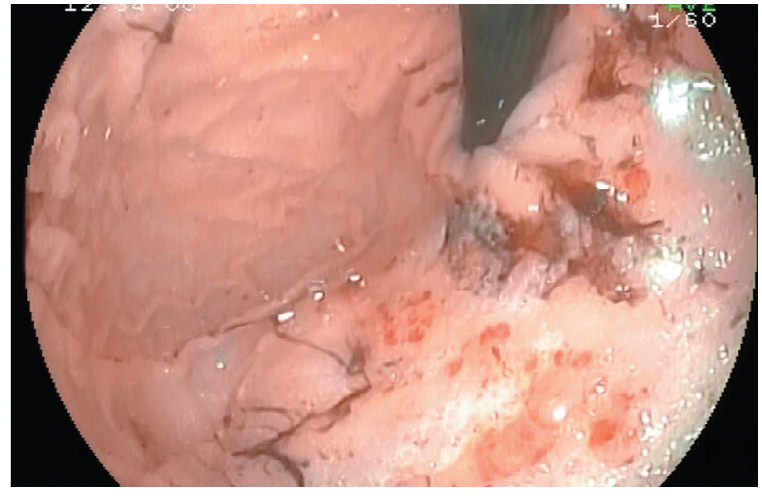

Рис. 1. Эндоскопическая картина геморрагического гастрита: слизистая оболочка желудка отечна, с множественными мелкими геморрагиями и пропотеванием крови через слизистую оболочку («плачущий кровью» желудок) при эозинофильном гастрите у больной 1 года 2 месяцев (клинический пример 1)

Иммуногистохимия: обнаружен $\operatorname{IgE}$ в слизистой оболочке желудка.

Получен положительный тест на дегрануляцию тучных клеток с белком коровьего молока, пшеницей, курицей, яйцом, рисом.

Установлен диагноз эозинофильного гастрита.

Назначена диета с исключением белка коровьего молока, пшеницы, курицы, яиц. На гипоаллергенной диете состояние нормализовалось, повторных кровотечений не было. Через год повторная эндоскопия и гистология патологии не выявили.

При эозинофильном гастроэнтерите чаще поражаются и желудок, и тонкая кишка. Клинически заболевание может манифестировать болями в животе, тошнотой, рвотой, может быть диарея, анемия, симптомы мальабсорбции. Очень характерна экссудативная энтеропатия, гипопротеинемия, могут быть отеки [32]. Эндоскопическая картина желудка и тонкой кишки чаще нормальная, но может наблюдаться гиперплазия лимфоидных фолликулов, реже эрозии и язвы. Видеокапсульная эндоскопия, проведенная этим больным, обнаружила по ходу тонкой кишки участки гиперемии, утраты ворсин, ульцерации, неполные стриктуры, что иногда становилось причиной застревания капсулы [33]. Рентгенологически характерна гипомоторная дискинезия, иногда признаки нодулярности и сужения кишки. Осложнения эозинофильного гастрита могут касаться как привратника (пилоростеноз), так и тонкой кишки (стеноз, перфорация).

Для гистологической картины заболевания характерны не только эозинофильная и лимфоцитарная инфильтрация, но также 

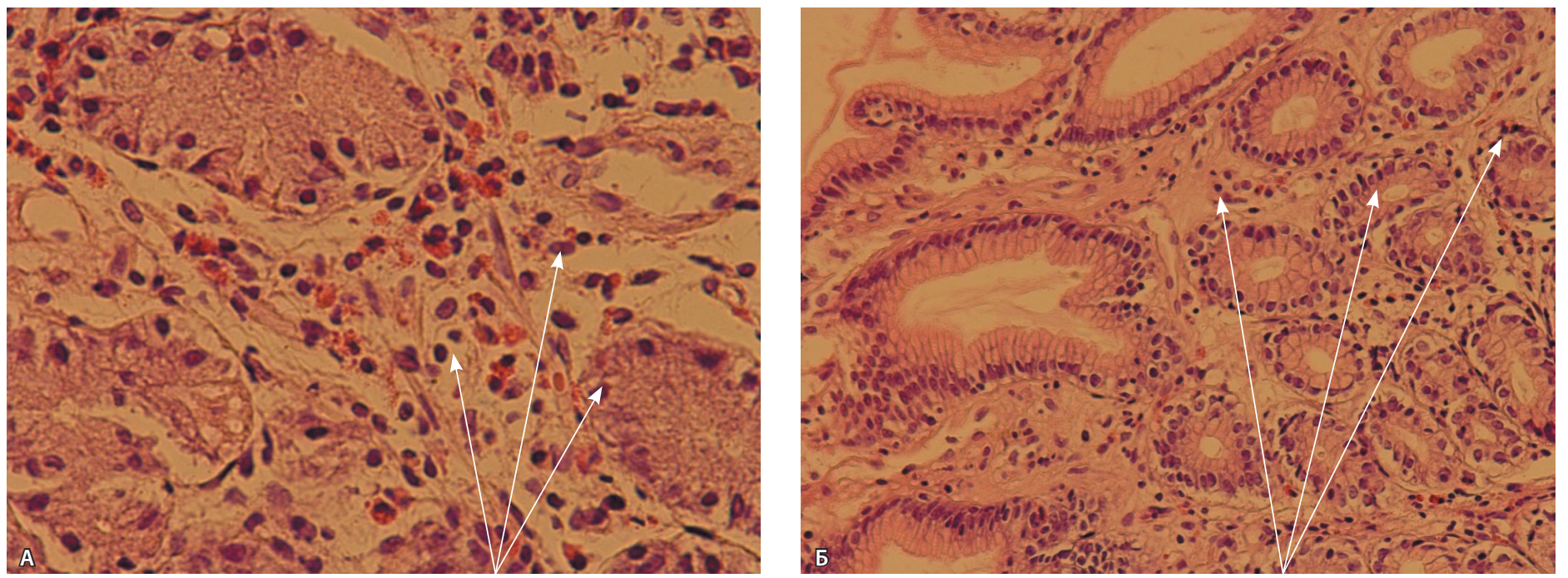

Рис. 2. Гистологическая картина эозинофильного гастрита (клинический пример 1): умеренная инфильтрация лимфоцитами, плазмоцитами с большим количеством эозинофилов (стрелки), нейтрофилы в небольшом количестве. Биоптат тела желудка; окраска гематоксилином и эозином; А ×600, Б×300

экстрацеллюлярные отложения эозинофильных гранул и эозинофильного катионного белка, эотаксина 1 и 2 , иногда присутствие гигантских мультинуклеаров [5].

Эозинофильный колит проявляется диареей, а также кровью в стуле, - картиной, сходной с воспалительными заболеваниями кишечника [34]. Эндоскопически в толстой кишке характерна очаговая гиперемия, исчезновение или смазанность сосудистого рисунка, лимфонодулярная гиперплазия. Характерно также увеличение лимфоидных фолликулов в подвздошной кишке (терминальный илеит), что иногда ошибочно расценивается как признак болезни Крона. Однако у части больных при эндоскопии не удается выявить никаких патологических изменений. Воспалительные изменения обнаруживают только при гистологическом и гистохимическом исследовании биоптатов толстой и подвздошной кишки. Как правило, это незначительное или умеренное воспаление с присутствием более 30 эозинофилов в поле зрения при большом увеличении, смешанная, преимущественно лимфоплазмоцитарная инфильтрация, гиперплазия лимфоидных фолликулов (клинический пример 2). При этом изменения могут быть не в каждом биоптате, так как для эозинофильных заболеваний ЖКТ характерно очаговое поражение, поэтому при проведении эндоскопии желательно брать несколько биоптатов из каждого отдела органа при любой визуальной картине. От воспалительных заболеваний кишечника эта форма отличается отсутствием лабораторной активности, невысоким уровнем кальпротектина, незначительной воспалительной активностью в слизистой оболочке кишечника по данным гистологического исследования.

\section{Клинический пример 2}

Больная Н. впервые поступила в гастроэнтерологическое отделение больницы в марте 2017 г. в возрасте 2 лет 7 месяцев с жалобами на наличие крови в стуле ежедневно в виде прожилок и капель алой крови. Амбулаторно были исключены кишечные инфекции: посев кала на острые кишечные инфекции, на кампилобактер, иммуноферментный анализ кала на токсины А и В Clostridium difficile, реакция непрямой гемагглютинации с кишечной группой - результаты отрицательные. Направлена с подозрением на воспалительные заболевания кишечника.

Ребенок от 1-й беременности, срочных родов, родилась с массой 3100 г, оценка по Апгар 8/9 баллов. На грудном вскармливании до 1 года 2 месяцев. Прикормы введены в срок. В первый год жизни росла и развивалась без особенностей, проявлений аллергии не было. С 1 года иногда бывали высыпания на коже после употребления курицы, винограда. У матери аллергический ринит.

При поступлении в клиническом анализе крови: тромбоцитоз - 450×109/л, снижение гемоглобина 102 г/л; в биохимическом анализе крови небольшое снижение общего белка - 60 г/л; кальпротектин кала 568 мкг/г (норма до 50 мкг/г); отрицательный результат выявления антител к Saccharomyces cerevisiae (ASCA) 

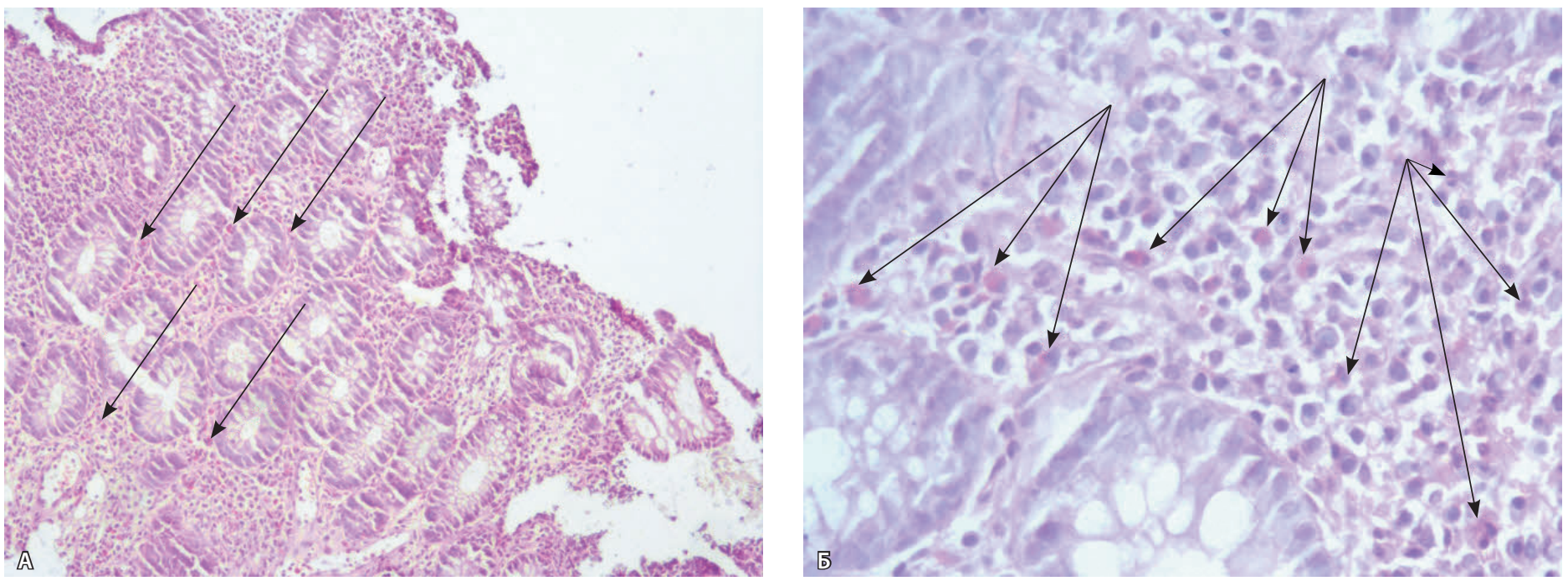

Рис. 3. Гистологическая картина эозинофильного колита у больной 2 лет 7 месяцев (клинический пример 2): отек, умеренная лимфоцитарная инфильтрация, значительное количество эозинофилов (стрелки). Биоптат толстой кишки; окраска гематоксилином и эозином; А ×40, $\mathbf{5} \times 400$

и обнаружения антинейтрофильных антител (ANCA), общий IgE в крови в норме. Специфические IgE не обнаружены. Тест на дегрануляцию тучных клеток с пищевыми аллергенами был положителен к белку коровьего молока, курице, пшенице.

На ЭГДС обнаружен нодулярный бульбит, поверхностный дуоденит с лимфостазом. Гистологически: слизистая оболочка желудка - картина соответствует поверхностному гастриту, минимальные проявления воспаления. Слизистая оболочка двенадцатиперстной кишки - картина соответствует хроническому дуодениту с легкой атрофией ворсин, активность воспаления низкая.

Проведена илеоколоноскопия: обнаружена выраженная лимфоидная гиперплазия в терминальном отделе подвздошной кишки, немногочисленные поверхностные язвы и эрозии в разных отделах толстой кишки. Гистологически: в подвздошной кишке ворсины пальцевидной и листовидной формы, уплощены. Крипты овальные, просветы крипт узкие, расположены неравномерно. Эпителий ворсин цилиндрический, сниженной высоты, количество межэпителиальных лейкоцитов слабо повышено, в их составе преобладают лимфоциты. Бокаловидные клетки в сниженном количестве. В строме отек, плотная неравномерная инфильтрация: плазматические клетки и лимфоциты в умеренном количестве, эозинофилы - 30-40 в ряде полей зрения, нейтрофилы в небольшом количестве. Несколько крупных лимфоидных фолликулов с развитыми герминативными центрами. Легкий фиброз стромы. Во всех отделах толстой кишки крипты округлой формы, просветы их узкие, архитектоника сохранена. Поверхностный эпителий цилиндрический, количество межэпителиальных лейкоцитов несколько повышено, в их составе преобладают лимфоциты. Бокаловидные клетки в достаточном количестве. В строме отек, в целом равномерная плотная инфильтрация: плазматические клетки, лимфоциты в умеренном количестве, эозинофилы до 50-70 в поле зрения, нейтрофилы в небольшом количестве. Заключение: картина соответствует терминальному илеиту, эозинофильному колиту (рис. 3).

Пациентке назначена гипоаллергенная диета: исключены все молочные продукты, пшеница, куриное яйцо, курица; введена смесь Алфаре Амино; назначен преднизолон 15 мг/сут (1 мг/кг/сут) с последующим снижением и отменой в течение 1,5 месяцев.

На фоне проводимой терапии отмечалась положительная клинико-лабораторная динамика: жалоб нет, параклинической активности нет, стул оформленный без крови и слизи.

Диагноз при выписке в марте 2017 г.: «эозинофильный колит (терминальный илеит, эрозивно-язвенный панколит). Пищевая аллергия (поливалентная сенсибилизация)».

Учитывая возможность вторичной эозинофилии на фоне болезни Крона и сходство эндоскопической картины, для установления окончательного диагноза было необходимо динамическое наблюдение.

В период с апреля 2017 по январь 2018 г. пациентка строго соблюдала гипоаллергенную диету, состояние оставалось стабильным, удовлетворительным, стул без патологии, после отмены преднизолона без ухудшения. 


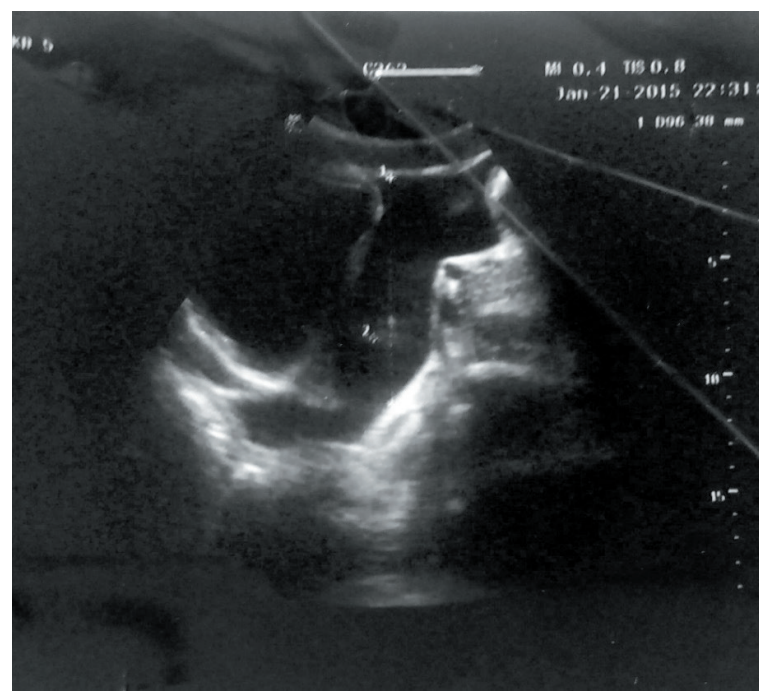

Рис. 4. Асцит по данным ультразвукового исследования у больного 16 лет (клинический пример 3)

С января 2018 г. родители самостоятельно расширили диету ребенка: введены вишневое варенье, красные яблоки, на этом фоне отмечено ухудшение состояния - вновь появилась примесь крови в стуле. В марте 2018 г. девочка повторно госпитализирована. Стул тогда был 2 раза в день, кашицеобразный, с примесью крови в виде капель и прожилок на поверхности кала.

В клиническом анализе крови отмечено увеличение скорости оседания эритроцитов до 20 мм/ч, в биохимическом анализе крови небольшая гипопротеинемия - 61 г/л; коагулограмма в пределах нормы; IgE общий и специфические в норме; антитела к тканевой трансглютаминазе, диамидированному пептиду глиадина (на целиакию) - в пределах нормы; кальпротектин в кале - более 600 мкг/г; иммуноферментный анализ на токсины А и В Clostridium difficile в кале отрицателен. ASCA, ANCA - отрицательны. Вновь проведено эндоскопическое исследование: ЭГДС без патологии. Илеоколоноскопия - катарально-фолликулярный колит. Гистологически: в слизистой оболочке толстой кишки умеренно выраженная инфильтрация, количество эозинофилов до 20-30 в поле зрения.

Диагноз: эозинофильный колит.

Была назначена гипоаллергенная диета с исключением белка коровьего молока, яиц, курицы, пшеницы, орехов, рыбы и морепродуктов, красных яблок, вишни; смесь Алфаре Амино. Назначен монтелукаст (препарат Сингуляр) 4 мг 1 раз в сутки в течение 3 месяцев.

На фоне коррекции диеты и проводимого лечения отмечалась быстрая нормализация стула, наблюдение в течение 6 месяцев патологии не выявило. Кальпротектин в кале через 3 и 6 месяцев в пределах нормы.

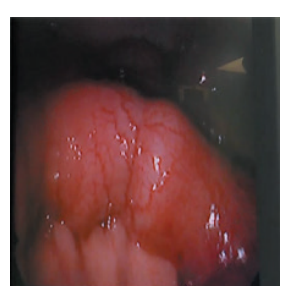

Рис. 5. Илеит при эозинофильном илеоколите по данным диагностической лапароскопии (клинический пример 3)
При эозинофильной инфильтрации мышечного слоя пищевода, желудка, кишечника может развиваться утолщение стенки, как следствие возможно формирование стеноза на любом уровне ЖКТ (например, стеноз пищевода, пилоростеноз). При эозинофильном воспалении серозной оболочки кишки развивается асцит (клинический пример 3), отличающийся от других форм высоким содержанием эозинофилов в экссудате, а также в периферической крови [32].

\section{Клинический пример 3}

Больной К., 16 лет, поступил с жалобами на увеличение живота, стул 3-5 раз в день, водянистый, слабость, потерю веса, плохой аппетит.

Болен около 1 месяца. Температура не повышалась. Амбулаторно получил курс антибиотиков - без эффекта.

В анамнезе: в возрасте до 3 лет проявления респираторной аллергии (аллергический ринотрахеобронхит), эпизодические проявления пищевой аллергии в виде сыпи (на какие продукты, не установлено).

Объективно при поступлении: состояние средней тяжести, физическое развитие соответствует возрасту. Кожа, видимые слизистые оболочки чистые, обычной окраски. Тоны сердца ритмичные, артериальное давление 120/65 мм рт. ст., частота сердечных сокращений 78 ударов в минуту. Дыхание везикулярное. Живот симметричный, значительно увеличен в размерах, проведение глубокой пальпации невозможно. Перкуторно определяется жидкость в брюшной полости. Печень выступает на 2 см из-под края реберной дуги. Селезенка не пальпируется.

В клиническом анализе крови: тромбоцитоз $462 \times 10^{9} / л ;$ в биохимическом анализе крови: общий белок 55 г/л, остальные показатели в норме.

При ультразвуковом исследовании обнаружено большое количество жидкости в брюшной полости (рис. 4).

Проведена диагностическая лапароскопия (рис. 5): в брюшной полости определяется выпот в количестве 2 литров, прозрачный, желтый (взят на цитологию). Брюшина не изменена. Печень гладкая, без макроскопических изменений, селезенка не изменена. В брыжейке кишки увеличенных лимфоузлов не определяется. В дистальных отделах тонкой кишки стенка утолщена за счет отека, гиперемирована с мелкими кровоизлияниями. Патологических образований в брюшной полости не определяется. Цитология асцитической жидкости: атипичные клетки не обнаружены, отмечается умеренное количество лимфоцитов, макрофагов и эозинофилов; количество общего белка повышено до 56,5 г/л. 

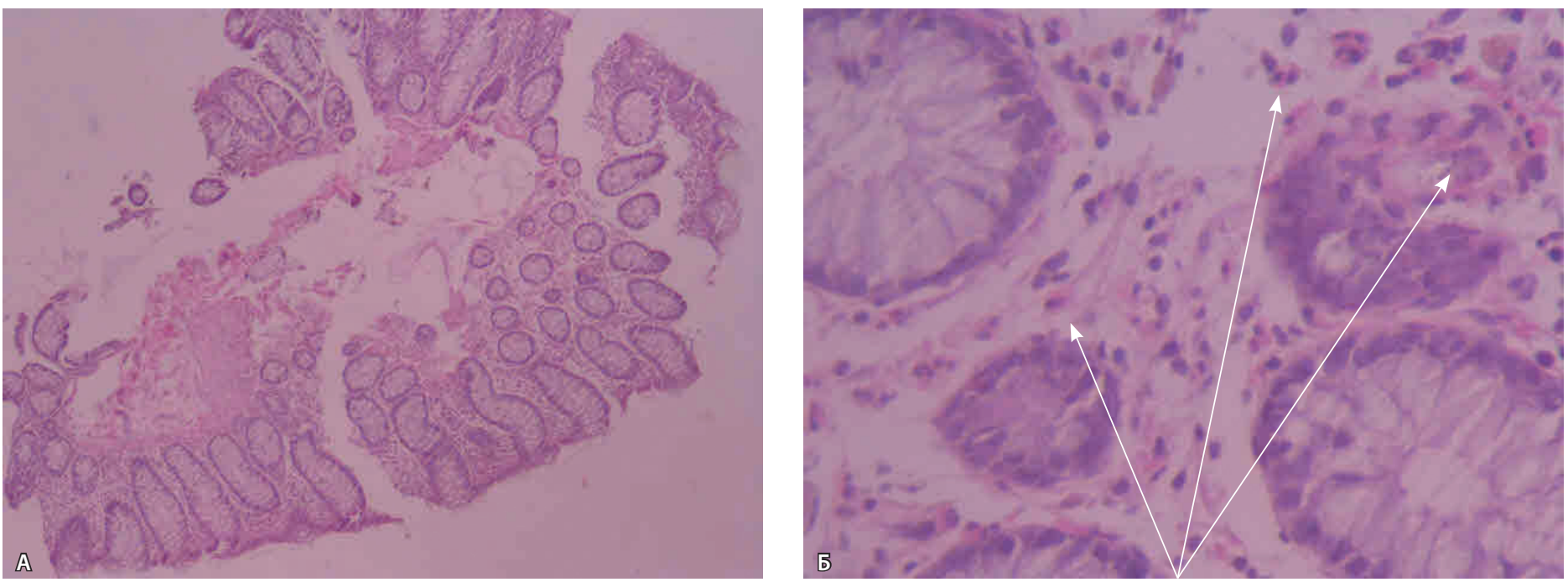

Рис. 6. Гистологическая картина эозинофильного колита у пациента 16 лет (клинический пример 3): незначительная инфильтрация стромы, повышено количество эозинофилов (стрелки). Биоптат толстой кишки; окраска гематоксилином и эозином; А × 40, Б×400

При ЭГДС - поверхностный гастродуоденит, выявлена Helicobacter pylori (по данным быстрого уреазного теста). В кале обнаружены лямблии.

Илеоколоноскопия: терминальный илеит (гиперплазия лимфоидных фолликулов в подвздошной кишке), толстая кишка визуально без патологии. Гистологически: эозинофильный илеоколит (до 30 эозинофилов в поле зрения при большом увеличении) (рис. 6).

IgE общий - 127 MЕ/мл (норма: от 0 до 87). По результатам исследования аспирата из двенадцатиперстной кишки обнаружено повышение специфических $\operatorname{IgE~к~пшенице~-~0,11~(норма:~от~} 0$ до 0,1 ) и к грече - 0,15 (норма: от 0 до 0,1 ).

Установлен диагноз. Основной: эозинофильный илеоколит. Осложнения: асцит. Сопутствующий: хронический гастродуоденит, НР(+). Лямблиоз.

Назначено лечение: диета с исключением пшеницы и гречи; метронидазол 1 г/сут 10 дней; преднизолон 40 мг с постепенным снижением в течение 2 месяцев.

На фоне лечения состояние быстро улучшилось, асцит полностью купирован через 2 недели, стул нормальный. Повторных эпизодов асцита не наблюдалось. При контрольном обследовании через 1 год эндоскопически в толстой кишке без патологии, в дистальном отделе подвздошной кишки небольшая гиперплазия лимфоидных фолликулов. Гистологически небольшая преимущественно лимфоплазмоцитарная инфильтрация, эозинофилы единичные.

Представленные примеры эозинофильных поражений ЖКТ клинически напоминали воспалительные заболевания кишечника, требовали дифференциальной диагностики с ними и динамического наблюдения для окончательной верификации диагноза, поскольку, как известно, эозинофильная инфильтрация может сопутствовать болезни Крона. На основании того, что во всех случаях элиминация пищевых антигенов и кратковременный курс глюкокортикостероидов приводили к стойкому исчезновению симптомов и признаков заболевания, как клинически, так и гистологически, и после полной отмены медикаментозной терапии состояние пациентов оставалось удовлетворительным, а физическое развитие соответствовало возрастным темпам, эозинофильное поражение верифицировано в качестве основного диагноза и расценено как первичное.

Эозинофилы могут тесно взаимодействовать с нервными ганглиями энтеральной нервной системы ЖКТ, вызывать нарушение их регуляторной функции или даже воспаление (ганглионит), что объясняет частое нарушение моторики ЖКТ без формирования стеноза. Эти моторные нарушения ЖКТ проявляются дисфункцией сфинктеров, нарушением эвакуации из желудка, патологическими рефлюксами (гастроэзофагеальный и дуоденогастральный рефлюкс), упорными запорами, которые не поддаются терапии обычными осмотическими слабительными. При этом, как правило, больному ставят диагноз функциональных расстройств ЖКТ. Однако тщательное эндоскопическое, гистологическое исследование и пробная 
элиминационная диета могут стать основой для установления диагноза гастроинтестинальной аллергии. В частности, при хронических запоpax, не поддающихся обычной терапией осмотическими слабительными, исключение белка коровьего молока оказывается эффективным более чем в половине случаев, возобновление же молочной диеты вновь приводит к усилению запоров, что подтверждает их аллергический генез [35].

В 50\% случаев у больных с установленной одной локализацией эозинофильных заболеваний ЖКТ обнаруживают симптомы или признаки и другой, например, при эозинофильном гастроэнтерите возможен эозинофильный эзофагит или колит [17].

В последние годы описано возможное вовлечение билиопанкреатической зоны при эозинофильном гастроэнтерите. У этих больных появляются симптомы холецистита, панкреатита с дилатацией желчных протоков, билиарной обструкцией и желтухой в сочетании с кишечными симптомами [32]. Эозинофильные поражения могут быть проявлением IgG4-ассоциированных заболеваний, при этом IgG4 может быть обнаружен иммуногистохимически в слизистой оболочке в участке эозинофильного поражения [36].

Эозинофильные заболевания ЖКТ следует дифференцировать с гиперэозинофильным синдромом - редким системным заболеванием, при котором эозинофильное воспаление органов сочетается с высокой эозинофилией в крови (абсолютное содержание более 1500/мм³ ) на протяжении более 6 месяцев. В костном мозге этих больных обнаружены тучные клетки с признаками дисплазии. Хороший эффект дает лечение ингибитором тирозинкиназы иматинибом [37].

\section{Лечение}

Лечение эозинофильных заболеваний ЖКТ пока недостаточно разработано. Элиминационная диета, переход на высоко гидролизованную или даже аминокислотную смесь оказываются эффективными примерно в 40\%. Чем младше ребенок, тем лучше он отвечает на элиминационную диету. У детей старшего возраста и взрослых в большинстве случаев требуется назначение медикаментозной терапии [38, 39].

Глюкокортикостероиды эффективны практически при всех видах эозинофильных заболеваний ЖКТ, но учитывая их нежелательные побочные эффекты, следует стремиться к их местному назначению, когда это возможно. Предпочтительны препараты с высокой аффинностью и минимальной системной биодоступностью (будесонид 3-9 мг/сут). При тяжелых формах эозинофильных заболеваний ЖКТ назначают системные стероиды - преднизолон из расчета 0,5-1 мг/кг/с. Эту дозу назначают на 7-10 дней с последующим постепенным снижением и полной отменой через 2-3 месяца.

В связи с ограниченным опытом лечения больных с эозинофильными заболеваниями ЖКТ в мире отработанной тактики медикаментозной терапии пока не существует. Описаны отдельные случаи или серии случаев успешного лечения кромогликатом натрия или недокромилом (20-40 мг/кг/с), которые стабилизируют мембраны тучных клеток; Н1-гистаминоблокатором кетотифеном (0,5-1 мг/с) [40]; ингибитором лейкотриенов монтелукастом (4-10 мг/с), особенно при гормонозависимости [41].

Есть единичные данные о применении антител к IL-5 (меполизумаб и реслизумаб) для лечения гиперэозинофильного синдрома. Пилотное исследование по использованию меполизумаба у пациентов с эозинофильным гастроэнтеритом показало снижение эозинофилии в крови и ткани на 70\%, но с минимальным уменьшением симптоматики при этом [42] и ее нарастанием после отмены препарата [43].

При осложнениях эозинофильных заболеваний ЖКТ (стеноз, перфорация) показано бужирование, оперативное лечение.

Катамнез больных эозинофильными заболеваниями ЖКТ недостаточно изучен. Согласно данным G. Pineton de Chambrun и соавт., наблюдавших 43 взрослых пациентов в течение 13 лет, у 42\% болезнь проявлялась только одним эпизодом с последующим полным выздоровлением, у 37\% симптомы периодически обострялись и у $21 \%$ персистировали постоянно. Более высокий риск последующих обострений имели те больные, у которых сохранялось повышенное количество эозинофилов в крови [39]. Дети раннего возраста имеют высокие шансы полного выздоровления при условии строгого соблюдения элиминационной диеты.

\section{Заключение}

Эозинофильные поражения ЖКТ - редкие, но растущие по частоте заболевания ЖКТ с хроническим рецидивирующим течением. Они обусловлены дисфункцией иммунной системы и могут быть вызваны пищевыми или респираторными аллергенами, однако установить причину у каждого конкретного пациента не всегда возможно. Как правило, уровень специфических 
$\operatorname{IgE~в~крови~не~повышен,~но~IgE~могут~быть~выяв-~}$ лены, как показали наши клинические примеры, местно: в биоптате ткани или в аспирате. Тест на дегрануляцию тучных клеток с пищевыми аллергенами демонстрирует положительные результаты и коррелирует с эффектом элиминации соответствующих продуктов практически у всех пациентов.

Среди эозинофильных заболеваний ЖКТ наиболее изучен эозинофильный эзофагит, но эозинофильное поражение возможно в любом отделе ЖКТ, оно может быть локальным и при этом на разной глубине - от слизистой до серозной оболочки. Диагноз устанавливают на основании обнаружения скоплений эозинофилов (в пищеводе выше 15 в поле зрения, в других отделах ЖКТ выше 20-30 в поле зрения при большом увеличении). Поскольку инфильтрация может быть очаговой, для достоверной диагностики необходимо брать несколько биоптатов. Можно предположить, что очаговость не позволяет верифицировать эозинофильные заболевания ЖКТ во всех случаях, воспалительный инфильтрат в других отделах может быть лимфоплазмоцитарным с небольшим количеством эозинофилов, что затрудняет трактовку. Именно поэтому разработка других, более точных методов диагностики (например, иммуногистохимических), представляется нам весьма перспективной.

Симптоматика эозинофильных поражений неспецифична и напоминает другие заболевания соответствующего органа: от функциональных расстройств до воспалительных

\section{Конфликт интересов}

Авторы декларируют отсутствие явных и потенциальных конфликтов интересов, связанных с публикацией настоящей статьи.

\section{Финансирование}

Работа проведена без привлечения дополнительного финансирования со стороны третьих лиц. заболеваний кишечника. Представленные в данной статье клинические примеры иллюстрируют многообразие форм эозинофильных заболеваний ЖКТ у детей. Лечение эозинофильных заболеваний ЖКТ находится в стадии разработки и не имеет пока в основе каких-либо масштабных многоцентровых исследований, а основывается на клиническом опыте. Однако элиминация причинно-значимого аллергена является основой лечения и может быть достаточной для достижения стойкого улучшения или даже полного выздоровления. Как правило, стандартные элиминационные диеты рекомендуют исключать из рациона белок коровьего молока, яйца, орехи, морепродукты, рыбу [27]. В описанных нами клинических наблюдениях у всех пациентов установлена сенсибилизация к злакам: пшенице, реже грече, рису. Таким образом, индивидуализация диеты с учетом данных теста на дегрануляцию тучных клеток может быть залогом ее результативности. В более тяжелых случаях показано назначение медикаментов: глюкокортикостероидов, монтелукаста, которые в совокупности с элиминационной диетой продемонстрировали эффективность с достижением клинического выздоровления у наблюдавшихся нами детей. Биологическая терапия эозинофильных заболеваний ЖКТ, которая разрабатывается в настоящее время, требует проведения клинических исследований и перспективна в тяжелых случаях при хроническом рецидивирующем течении или при развитии осложнений. ()

\section{Литература}

1. Платонова НБ. Аллергия к белкам коровьего молока. Педиатр. 2016;7(3):153-6. doi: 10.17816/PED73153-156.

2. Jensen ET, Martin CF, Kappelman MD, DelIon ES. Prevalence of eosinophilic gastritis, gastroenteritis, and colitis: Estimates from a National Administrative Database. J Pediatr Gastroenterol Nutr. 2016;62(1):36-42. doi: 10.1097/MPG.0000000000000865.

3. Collins $\mathrm{MH}$. Histopathology associated with eosinophilic gastrointestinal diseases. Immunol Allergy Clin North Am. 2009;29(1):109-17, x-xi. doi: 10.1016/j.iac.2008.10.005.

4. Choi JS, Choi SJ, Lee KJ, Kim A, Yoo JK, Yang HR, Moon JS, Chang JY, Ko JS, Kang GH. Clinical manifestations and treatment outcomes of eosinophilic gastroenteritis in children. Pediatr Gastroenterol Hepatol Nutr. 2015;18(4): 253-60. doi: 10.5223/pghn.2015.18.4.253.
5. Naramore S, Gupta SK. Nonesophageal eosinophilic gastrointestinal disorders: clinical care and future directions. J Pediatr Gastroenterol Nutr. 2018;67(3):318-21. doi: 10.1097/ MPG.0000000000002040.

6. Clayton F, Fang JC, Gleich GJ, Lucendo AJ, Olalla JM, Vinson LA, Lowichik A, Chen X, Emerson L, Cox K, O'Gorman MA, Peterson KA. Eosinophilic esophagitis in adults is associated with lgG4 and not mediated by lgE. Gastroenterology. 2014;147(3):602-9. doi: 10.1053/j. gastro.2014.05.036.

7. Klein NC, Hargrove RL, Sleisenger MH, Jeffries $\mathrm{GH}$. Eosinophilic gastroenteritis. Medicine (Baltimore). 1970;49(4):299-319.

8. Rothenberg ME. Eosinophilic gastrointestinal disorders (EGID). J Allergy Clin Immunol. 2004;113(1):11-28. doi: 10.1016/j. jaci.2003.10.047.
9. Fleischer DM, Atkins D. Evaluation of the patient with suspected eosinophilic gastrointestinal disease. Immunol Allergy Clin North Am. 2009;29(1):53-63, ix. doi: 10.1016/j. iac.2008.09.002.

10. Lucendo AJ, Arias A, De Rezende LC, Yagüe-Compadre JL, Mota-Huertas T, González-Castillo S, Cuesta RA, Tenias JM, Bellón T. Subepithelial collagen deposition, profibrogenic cytokine gene expression, and changes after prolonged fluticasone propionate treatment in adult eosinophilic esophagitis: a prospective study. J Allergy Clin Immunol. 2011;128(5):1037-46. doi: 10.1016/j. jaci.2011.08.007.

11. Straumann A, Conus S, Degen L, Felder S, Kummer M, Engel H, Bussmann C, Beglinger C, Schoepfer A, Simon HU. Budesonide is effective in adolescent and adult patients with active eosinophilic esophagitis. Gastroen- 
terology. 2010;139(5):1526-37, 1537.e1. doi: 10.1053/j.gastro.2010.07.048.

12. Aceves SS, Newbury RO, Chen D, Mueller J, Dohil R, Hoffman H, Bastian JF, Broide DH. Resolution of remodeling in eosinophilic esophagitis correlates with epithelial response to topical corticosteroids. Allergy. 2010;65(1):109-16. doi: 10.1111/j.13989995.2009.02142.x.

13. Straumann A, Conus S, Degen L, Frei C, Bussmann C, Beglinger C, Schoepfer A, Simon HU. Long-term budesonide maintenance treatment is partially effective for patients with eosinophilic esophagitis. Clin Gastroenterol Hepatol. 2011;9(5):400-9.e1. doi: 10.1016/j.cgh.2011.01.017.

14. Collins MH. Histopathologic features of eosinophilic esophagitis and eosinophilic gastrointestinal diseases. Gastroenterol Clin North Am. 2014;43(2):257-68. doi: 10.1016/j. gtc.2014.02.007.

15. Jawairia M, Shahzad G, Mustacchia P. Eosinophilic gastrointestinal diseases: review and update. ISRN Gastroenterol. 2012;2012:463689. doi: $10.5402 / 2012 / 463689$.

16. Ziegler SF. The role of thymic stromal lymphopoietin (TSLP) in allergic disorders. Curr Opin Immunol. 2010;22(6):795-9. doi: 10.1016/j. coi.2010.10.020.

17. Valent $P$, Klion AD, Rosenwasser LJ, Arock M, Bochner BS, Butterfield JH, Gotlib J, Haferlach T, Hellmann A, Horny HP, Leiferman KM, Metzgeroth G, Matsumoto K, Reiter A, Roufosse $F$, Rothenberg ME, Simon HU, Sotlar $K$, Vandenberghe P, Weller PF, Gleich GJ. ICON: eosinophil disorders. World Allergy Organ J. 2012;5(12):174-81. doi: 10.1097/WOX. Ob013e31827f4192.

18. Prasad GA, Alexander JA, Schleck CD, Zinsmeister AR, Smyrk TC, Elias RM, Locke GR $3^{\text {rd }}$, Talley NJ. Epidemiology of eosinophilic esophagitis over three decades in Olmsted County, Minnesota. Clin Gastroenterol Hepatol. 2009;7(10):1055-61. doi: 10.1016/j. cgh.2009.06.023.

19. Коростовцев ДС, Корниенко ЕА, Галенко ЛА, Трусова ОВ, Камаев АВ, Макарова ИВ. Желудочно-кишечные проявления пищевой аллергии: патогенез, клинические формы, принципы терапии. Российский аллергологический журнал. 2014;(3):11-21.

20. Hruz P, Straumann A, Bussmann C, Heer P, Simon $\mathrm{HU}$, Zwahlen $M$, Beglinger $C$, Schoepfer AM; Swiss EoE study group. Escalating incidence of eosinophilic esophagitis: a 20-year prospective, population-based study in Olten County, Switzerland. J Allergy Clin Immunol. 2011;128(6):1349-50.e5. doi: 10.1016/j. jaci.2011.09.013.

21. Roy-Ghanta S, Larosa DF, Katzka DA. Atopic characteristics of adult patients with eosinophilic esophagitis. Clin Gastroenterol
Hepatol. 2008;6(5):531-5. doi: 10.1016/j. cgh.2007.12.045.

22. Erwin EA, James HR, Gutekunst HM, Russo JM, Kelleher KJ, Platts-Mills TA. Serum IgE measurement and detection of food allergy in pediatric patients with eosinophilic esophagitis. Ann Allergy Asthma Immunol. 2010;104(6): 496-502. doi: 10.1016/j.anai.2010.03.018.

23. Almansa C, Krishna M, Buchner AM, Ghabril MS, Talley N, DeVault KR, Wolfsen H, Raimondo M, Guarderas JC, Achem SR. Seasonal distribution in newly diagnosed cases of eosinophilic esophagitis in adults. Am J Gastroenterol. 2009;104(4):828-33. doi: 10.1038/ ajg.2008.169.

24. Moawad FJ, Veerappan GR, Lake JM, Maydonovitch CL, Haymore BR, Kosisky SE, Wong RK. Correlation between eosinophilic oesophagitis and aeroallergens. Aliment Pharmacol Ther. 2010;31(4):509-15. doi: 10.1111/j.13652036.2009.04199.x.

25. Wang FY, Gupta SK, Fitzgerald JF. Is there a seasonal variation in the incidence or intensity of allergic eosinophilic esophagitis in newly diagnosed children? J Clin Gastroenterol. 2007;41(5):451-3. doi: 10.1097/01. mcg.0000248019.16139.67.

26. Spergel JM, Brown-Whitehorn TF, Beausoleil JL, Franciosi J, Shuker M, Verma R, Liacouras CA. 14 years of eosinophilic esophagitis: clinical features and prognosis. J Pediatr Gastroenterol Nutr. 2009;48(1):30-6. doi: 10.1097/MPG.0b013e3181788282.

27. Lucendo AJ, Molina-Infante J, Arias Á, von Arnim U, Bredenoord AJ, Bussmann C, Amil Dias J, Bove M, González-Cervera J, Larsson H, Miehlke S, Papadopoulou A, RodríguezSánchez J, Ravelli A, Ronkainen J, Santander C, Schoepfer AM, Storr MA, Terreehorst I, Straumann A, Attwood SE. Guidelines on eosinophilic esophagitis: evidence-based statements and recommendations for diagnosis and management in children and adults. United European Gastroenterol J. 2017;5(3):33558. doi: $10.1177 / 2050640616689525$.

28. Walsh SV, Antonioli DA, Goldman H, Fox VL, Bousvaros A, Leichtner AM, Furuta GT. Allergic esophagitis in children: a clinicopathological entity. Am J Surg Pathol. 1999;23(4):390-6.

29. Fox VL. Pediatric endoscopy. Gastrointest Endosc Clin N Am. 2000;10(1):175-94, viii.

30. Spechler SJ, Genta RM, Souza RF. Thoughts on the complex relationship between gastroesophageal reflux disease and eosinophilic esophagitis. Am J Gastroenterol. 2007;102(6):1301-6. doi: 10.1111/j.15720241.2007.01179.x.

31. Rothenberg ME, Mishra A, Collins MH, Putnam PE. Pathogenesis and clinical features of eosinophilic esophagitis. J Allergy Clin Immunol. 2001;108(6):891-4. doi: 10.1067/ mai.2001.120095.
32. Kelly KJ. Eosinophilic gastroenteritis. J Pediatr Gastroenterol Nutr. 2000;30 Suppl:S28-35.

33. Pasha SF, Leighton JA, Williams JW, De Petris G, Harold K, Shiff AA. Capsule retention in a patient with eosinophilic gastroenteritis mimicking diaphragm disease of the small bowel. Endoscopy. 2009;41 Suppl 2:E290-1. doi: 10.1055/s-0029-1215125.

34. Lemale J, Dainese L, Tounian P. Eosinophilic gastroenteritis and colitis in pediatric patients: Increasingly frequent diseases. Arch Pediatr. 2015;22(7):769-77. doi: 10.1016/j. arcped.2015.04.005.

35. lacono G, Cavataio F, Montalto G, Florena A, Tumminello $M$, Soresi $M$, Notarbartolo $A$, Carroccio A. Intolerance of cow's milk and chronic constipation in children. $\mathrm{N}$ Engl J Med. 1998;339(16):1100-4. doi: 10.1056/ NEJM199810153391602.

36. Zukerberg L, Mahadevan K, Selig M, Deshpande V. Oesophageal intrasquamous IgG4 deposits: an adjunctive marker to distinguish eosinophilic oesophagitis from reflux oesophagitis. Histopathology. 2016;68(7): 968-76. doi: 10.1111/his.12892.

37. Kuang FL, Klion AD. Biologic agents for the treatment of hypereosinophilic syndromes. J Allergy Clin Immunol Pract. 2017;5(6):15029. doi: 10.1016/j.jaip.2017.08.001.

38. Prussin C. Eosinophilic gastroenteritis and related eosinophilic disorders. Gastroenterol Clin North Am. 2014;43(2):317-27. doi: 10.1016/j.gtc.2014.02.013.

39. Pineton de Chambrun G, Gonzalez F, Canva JY, Gonzalez S, Houssin L, Desreumaux P, Cortot A, Colombel JF. Natural history of eosinophilic gastroenteritis. Clin Gastroenterol Hepatol. 2011;9(11):950-6.e1. doi: 10.1016/j. cgh.2011.07.017.

40. Suzuki J, Kawasaki Y, Nozawa R, Isome M, Suzuki S, Takahashi A, Suzuki H. Oral disodium cromoglycate and ketotifen for a patient with eosinophilic gastroenteritis, food allergy and protein-losing enteropathy. Asian Pac J Allergy Immunol. 2003;21(3):193-7.

41. De Maeyer N, Kochuyt AM, Van Moerkercke W, Hiele M. Montelukast as a treatment modality for eosinophilic gastroenteritis. Acta Gastroenterol Belg. 2011;74(4):570-5.

42. Prussin C, James SP, Huber MM, Klion $A D$, Metcalfe DD. Pilot study of anti-IL-5 in eosinophilic gastroenteritis. J Allergy Clin Immunol. 2003;111(2 Suppl 3):S275. doi: 10.1016/S00916749(03)80986-7.

43. Kim YJ, Prussin C, Martin B, Law MA, Haverty TP, Nutman TB, Klion D. Rebound eosinophilia after treatment of hypereosinophilic syndrome and eosinophilic gastroenteritis with monoclonal anti-IL-5 antibody SCH55700. J Allergy Clin Immunol. 2004;114(6):1449-55. doi: 10.1016/j.jaci.2004.08.027. 


\section{References}

1.Platonova NB. Allergy to cow's milk protein. Pediatrician (St. Petersburg). 2016;7(3):153-6. Russian. doi: 10.17816/PED73153-156.

2. Jensen ET, Martin CF, Kappelman MD, DelIon ES. Prevalence of eosinophilic gastritis, gastroenteritis, and colitis: Estimates from a National Administrative Database. J Pediatr Gastroenterol Nutr. 2016;62(1):36-42. doi: 10.1097/MPG.0000000000000865.

3. Collins $\mathrm{MH}$. Histopathology associated with eosinophilic gastrointestinal diseases. Immunol Allergy Clin North Am. 2009;29(1):109-17, x-xi. doi: 10.1016/j.iac.2008.10.005.

4. Choi JS, Choi SJ, Lee KJ, Kim A, Yoo JK, Yang HR, Moon JS, Chang JY, Ko JS, Kang GH. Clinical manifestations and treatment outcomes of eosinophilic gastroenteritis in children. Pediatr Gastroenterol Hepatol Nutr. 2015;18(4): 253-60. doi: 10.5223/pghn.2015.18.4.253.

5. Naramore S, Gupta SK. Nonesophageal eosinophilic gastrointestinal disorders: clinical care and future directions. J Pediatr Gastroenterol Nutr. 2018;67(3):318-21. doi: 10.1097/ MPG.0000000000002040.

6. Clayton F, Fang JC, Gleich GJ, Lucendo AJ, Olalla JM, Vinson LA, Lowichik A, Chen X, Emerson L, Cox K, O'Gorman MA, Peterson KA. Eosinophilic esophagitis in adults is associated with IgG4 and not mediated by IgE. Gastroenterology. 2014;147(3):602-9. doi: 10.1053/j. gastro.2014.05.036.

7. Klein NC, Hargrove RL, Sleisenger MH, Jeffries GH. Eosinophilic gastroenteritis. Medicine (Baltimore). 1970;49(4):299-319.

8. Rothenberg ME. Eosinophilic gastrointestinal disorders (EGID). J Allergy Clin Immunol. 2004;113(1):11-28. doi: 10.1016/j. jaci.2003.10.047.

9. Fleischer DM, Atkins D. Evaluation of the patient with suspected eosinophilic gastrointestinal disease. Immunol Allergy Clin North Am. 2009;29(1):53-63, ix. doi: 10.1016/j. iac.2008.09.002.

10. Lucendo AJ, Arias A, De Rezende LC, Yagüe-Compadre $\mathrm{J}$, Mota-Huertas $\mathrm{T}$, González-Castillo S, Cuesta RA, Tenias JM, Bellón T. Subepithelial collagen deposition, profibrogenic cytokine gene expression, and changes after prolonged fluticasone propionate treatment in adult eosinophilic esophagitis: a prospective study. J Allergy Clin Immunol. 2011;128(5):1037-46. doi: 10.1016/j. jaci.2011.08.007.

11. Straumann A, Conus S, Degen L, Felder S, Kummer M, Engel H, Bussmann C, Beglinger C, Schoepfer A, Simon HU. Budesonide is effective in adolescent and adult patients with active eosinophilic esophagitis. Gastroenterology. 2010;139(5):1526-37, 1537.e1. doi: 10.1053/j.gastro.2010.07.048.

12. Aceves SS, Newbury RO, Chen D, Mueller J, Dohil R, Hoffman H, Bastian JF, Broide DH. Resolu- tion of remodeling in eosinophilic esophagitis correlates with epithelial response to topical corticosteroids. Allergy. 2010;65(1):109-16. doi: 10.1111/j.1398-9995.2009.02142.x.

13. Straumann A, Conus S, Degen L, Frei C, Bussmann C, Beglinger C, Schoepfer A, Simon HU. Long-term budesonide maintenance treatment is partially effective for patients with eosinophilic esophagitis. Clin Gastroenterol Hepatol. 2011;9(5):400-9.e1. doi: 10.1016/j.cgh.2011.01.017.

14. Collins MH. Histopathologic features of eosinophilic esophagitis and eosinophilic gastrointestinal diseases. Gastroenterol Clin North Am. 2014;43(2):257-68. doi: 10.1016/j. gtc.2014.02.007.

15. Jawairia M, Shahzad G, Mustacchia P. Eosinophilic gastrointestinal diseases: review and update. ISRN Gastroenterol. 2012;2012:463689. doi: 10.5402/2012/463689.

16.Ziegler SF. The role of thymic stromal lymphopoietin (TSLP) in allergic disorders. Curr Opin Immunol. 2010;22(6):795-9. doi: 10.1016/j. coi.2010.10.020.

17. Valent $P$, Klion AD, Rosenwasser LJ, Arock $M$, Bochner BS, Butterfield JH, Gotlib J, Haferlach T, Hellmann A, Horny HP, Leiferman KM, Metzgeroth G, Matsumoto K, Reiter A, Roufosse $F$, Rothenberg ME, Simon HU, Sotlar K, Vandenberghe P, Weller PF, Gleich GJ. ICON: eosinophil disorders. World Allergy Organ J. 2012;5(12):174-81. doi: 10.1097/WOX. 0b013e31827f4192.

18. Prasad GA, Alexander JA, Schleck CD, Zinsmeister AR, Smyrk TC, Elias RM, Locke GR $3^{\text {rd }}$, Talley NJ. Epidemiology of eosinophilic esophagitis over three decades in Olmsted County, Minnesota. Clin Gastroenterol Hepatol. 2009;7(10):1055-61. doi: 10.1016/j. cgh.2009.06.023.

19. Korostovtsev DS, Kornienko EA, Galenko LA, Trusova OV, Kamaev AV, Makarova IV. Gastrointestinal manifestations of food allergy: pathogenesis, clinical forms and clues to therapy. Russian Allergology Journal. 2014;(3): 11-21. Russian.

20. Hruz P, Straumann A, Bussmann C, Heer P, Simon HU, Zwahlen $M$, Beglinger $C$, Schoepfer AM; Swiss EoE study group. Escalating incidence of eosinophilic esophagitis: a 20-year prospective, population-based study in Olten County, Switzerland. J Allergy Clin Immunol. 2011;128(6):1349-50.e5. doi: 10.1016/j. jaci.2011.09.013.

21. Roy-Ghanta S, Larosa DF, Katzka DA. Atopic characteristics of adult patients with eosinophilic esophagitis. Clin Gastroenterol Hepatol. 2008;6(5):531-5. doi: 10.1016/j. cgh.2007.12.045.

22. Erwin EA, James HR, Gutekunst HM, Russo JM, Kelleher KJ, Platts-Mills TA. Serum IgE measurement and detection of food allergy in pe- diatric patients with eosinophilic esophagitis. Ann Allergy Asthma Immunol. 2010;104(6): 496-502. doi: 10.1016/j.anai.2010.03.018.

23. Almansa C, Krishna M, Buchner AM, Ghabril MS, Talley N, DeVault KR, Wolfsen H, Raimondo M, Guarderas JC, Achem SR. Seasonal distribution in newly diagnosed cases of eosinophilic esophagitis in adults. Am J Gastroenterol. 2009;104(4):828-33. doi: 10.1038/ ajg.2008.169.

24. Moawad FJ, Veerappan GR, Lake JM, Maydonovitch $\mathrm{CL}$, Haymore BR, Kosisky SE, Wong RK. Correlation between eosinophilic oesophagitis and aeroallergens. Aliment Pharmacol Ther. 2010;31(4):509-15. doi: 10.1111/j.13652036.2009.04199.x.

25. Wang FY, Gupta SK, Fitzgerald JF. Is there a seasonal variation in the incidence or intensity of allergic eosinophilic esophagitis in newly diagnosed children? J Clin Gastroenterol. 2007;41(5):451-3. doi: 10.1097/01. mcg.0000248019.16139.67.

26. Spergel JM, Brown-Whitehorn TF, Beausoleil JL, Franciosi J, Shuker M, Verma R, Liacouras CA. 14 years of eosinophilic esophagitis: clinical features and prognosis. J Pediatr Gastroenterol Nutr. 2009;48(1):30-6. doi: 10.1097/MPG.0b013e3181788282.

27. Lucendo AJ, Molina-Infante J, Arias Á, von Arnim U, Bredenoord AJ, Bussmann C, Amil Dias J, Bove M, González-Cervera J, Larsson H, Miehlke S, Papadopoulou A, Rodríguez-Sánchez J, Ravelli A, Ronkainen J, Santander C, Schoepfer AM, Storr MA, Terreehorst I, Straumann A, Attwood SE. Guidelines on eosinophilic esophagitis: evidence-based statements and recommendations for diagnosis and management in children and adults. United European Gastroenterol J. 2017;5(3):33558. doi: $10.1177 / 2050640616689525$.

28. Walsh SV, Antonioli DA, Goldman H, Fox VL, Bousvaros A, Leichtner AM, Furuta GT. Allergic esophagitis in children: a clinicopathological entity. Am J Surg Pathol. 1999;23(4):390-6.

29. Fox VL. Pediatric endoscopy. Gastrointest Endosc Clin N Am. 2000;10(1):175-94, viii.

30. Spechler SJ, Genta RM, Souza RF. Thoughts on the complex relationship between gastroesophageal reflux disease and eosinophilic esophagitis. Am J Gastroenterol. 2007;102(6):1301-6. doi: 10.1111/j.15720241.2007.01179.x.

31. Rothenberg ME, Mishra A, Collins MH, Putnam PE. Pathogenesis and clinical features of eosinophilic esophagitis. J Allergy Clin Immunol. 2001;108(6):891-4. doi: 10.1067/ mai.2001.120095.

32. Kelly KJ. Eosinophilic gastroenteritis. J Pediatr Gastroenterol Nutr. 2000;30 Suppl:S28-35.

33. Pasha SF, Leighton JA, Williams JW, De Petris G, Harold K, Shiff AA. Capsule retention in a patient with eosinophilic gastroenteritis 
mimicking diaphragm disease of the small bowel. Endoscopy. 2009;41 Suppl 2:E290-1. doi: 10.1055/s-0029-1215125.

34. Lemale J, Dainese L, Tounian P. Eosinophilic gastroenteritis and colitis in pediatric patients: Increasingly frequent diseases. Arch Pediatr. 2015;22(7):769-77. doi: 10.1016/j. arcped.2015.04.005.

35. lacono G, Cavataio F, Montalto G, Florena A, Tumminello $M$, Soresi $M$, Notarbartolo $A$, Carroccio A. Intolerance of cow's milk and chronic constipation in children. $\mathrm{N}$ Engl J Med. 1998;339(16):1100-4. doi: 10.1056/ NEJM199810153391602.

36. Zukerberg L, Mahadevan K, Selig M, Deshpande V. Oesophageal intrasquamous IgG4 deposits: an adjunctive marker to distinguish eosinophilic oesophagitis from reflux oesophagitis. Histopathology. 2016;68(7): 968-76. doi: 10.1111/his.12892.
37. Kuang $\mathrm{FL}$, Klion $\mathrm{AD}$. Biologic agents for the treatment of hypereosinophilic syndromes. J Allergy Clin Immunol Pract. 2017;5(6):15029. doi: 10.1016/j.jaip.2017.08.001.

38. Prussin C. Eosinophilic gastroenteritis and related eosinophilic disorders. Gastroenterol Clin North Am. 2014;43(2):317-27. doi: 10.1016/j.gtc.2014.02.013.

39. Pineton de Chambrun G, Gonzalez F, Canva JY, Gonzalez S, Houssin L, Desreumaux P, Cortot A, Colombel JF. Natural history of eosinophilic gastroenteritis. Clin Gastroenterol Hepatol. 2011;9(11):950-6.e1. doi: 10.1016/j. cgh.2011.07.017.

40. Suzuki J, Kawasaki Y, Nozawa R, Isome M, Suzuki S, Takahashi A, Suzuki H. Oral disodium cromoglycate and ketotifen for a patient with eosinophilic gastroenteritis, food allergy and protein-losing enteropathy. Asian Pac J Allergy Immunol. 2003;21(3):193-7.

\title{
Eosinophilic disorders of the gastrointestinal tract: clinical manifestations, diagnosis and treatment
}

\author{
E.A. Kornienko ${ }^{1}$ Yu.A. Moiseenkova ${ }^{2}$ N.L. Volkova ${ }^{1}$ \\ T.B. Loboda'
}

Eosinophilic gastrointestinal disorders (EGID) are a kind of pathology which has not been well studied and has a trend to an increase during the last years that raises concern. They may have highly variable clinical manifestations; therefore, their differential diagnosis is not infrequently challenging. The article presents a review of scientific data on EGID and three clinical cases of various eosinophilic lesions of the stomach and gut in children. Clinical manifestations of EGID depend on their location and on the depth of the lesions. The first clinical case presented with repeated gastrointestinal bleedings in a child with hemorrhagic eosinophilic gastritis. The second clinical case was eosinophilic colitis with Crohn-like clinical and endoscopic manifestations, and the third one was eosinophilic ileocolitis with ascites. All these children had a background of sensitization to various food allergens. However, there were no high specific $\lg E$ in blood in any of the cases, although $\lg E$ were identified in the biopsy sample of intestinal mucosa and in duodenal aspirates. The results of the mast cell degranulation test with corresponding allergens correlated with the efficacy of their elimination. Elimination diet was recommended to all the patients; in two patients it was combined with a short course of glucocorticosteroids and in one case with subsequent montelucast treatment. All three patients achieved complete recovery, confirmed by their follow-up and repeated endoscopic and histological examinations.

Key words: eosinophilic gastritis, eosinophilic gastroenteritis, eosinophilic colitis, eosinophilic gastrointestinal disorder

For citation: Kornienko EA, Moiseenkova YuA, Volkova NL, Loboda TB. Eosinophilic disorders of the gastrointestinal tract: clinical manifestations, diagnosis and treatment. Almanac of Clinical Medicine. 2018;46(5):482-96. doi: 10.18786/2072-0505-2018-465-482-496

Received 17 August 2018;

accepted 25 September 2018
41. De Maeyer N, Kochuyt AM, Van Moerkercke W, Hiele M. Montelukast as a treatment modality for eosinophilic gastroenteritis. Acta Gastroenterol Belg. 2011;74(4):570-5.

42. Prussin C, James SP, Huber MM, Klion AD, Metcalfe DD. Pilot study of anti-IL-5 in eosinophilic gastroenteritis. J Allergy Clin Immunol. 2003;111(2 Suppl 3):S275. doi: 10.1016/S0091 6749(03)80986-7.

43. Kim YJ, Prussin C, Martin B, Law MA, Haverty TP, Nutman TB, Klion D. Rebound eosinophilia after treatment of hypereosinophilic syndrome and eosinophilic gastroenteritis with monoclonal anti-IL-5 antibody SCH55700. J Allergy Clin Immunol. 2004;114(6):1449-55. doi: 10.1016/j.jaci.2004.08.027.
Elena A. Kornienko - MD, PhD, Professor, Head of the Chair of Gastroenterology, Faculty of Postgraduate and Additional Professional Education $\triangle 2$ Litovskaya ul., Saint Petersburg, 194100 , Russian Federation. Tel.: +7 (812) 7780661. E-mail: elenkornienk@yandex.ru

Yuliya A. Moiseenkova - MD, Department of Gastroenterology2

Nataliya L. Volkova - MD, Head of the Department of Gastroenterology, Clinical Hospital ${ }^{1}$

Tatiyana B. Loboda - MD, PhD, Associate Professor, Chair of Gastroenterology, Faculty of Postgraduate and Additional Professional Education'

\section{Conflict of interests}

The authors declare no conflicts of interests related to the study.

${ }^{2}$ St. Mary Magdalene Children's City Hospital No. 2; 47 2-ya liniya Vasil'evskogo ostrova, Saint Petersburg, 199053, Russian Federation 